\title{
Norois
}

Environnement, aménagement, société

$233 \mid 2014$

Mobilité, santé et développement territorial : de nouveaux défis pour la gouvernance des territoires

ruraux

\section{Bretagne, Guide géologique}

\section{Maxime Hoffman}

\section{(2) OpenEdition}

\section{Journals}

Édition électronique

URL : http://journals.openedition.org/norois/5433

DOI : $10.4000 /$ norois. 5433

ISBN : 978-2-7535-4127-6

ISSN : $1760-8546$

\section{Éditeur}

Presses universitaires de Rennes

\section{Édition imprimée}

Date de publication : 20 décembre 2014

Pagination : 83-84

ISBN : 978-2-7535-4083-5

ISSN : 0029-182X

\section{Référence électronique}

Maxime Hoffman, «Bretagne, Guide géologique », Norois [En ligne], 233 | 2014, mis en ligne le 20 décembre 2014, consulté le 25 septembre 2020. URL : http://journals.openedition.org/norois/5433 ; DOI : https://doi.org/10.4000/norois.5433 


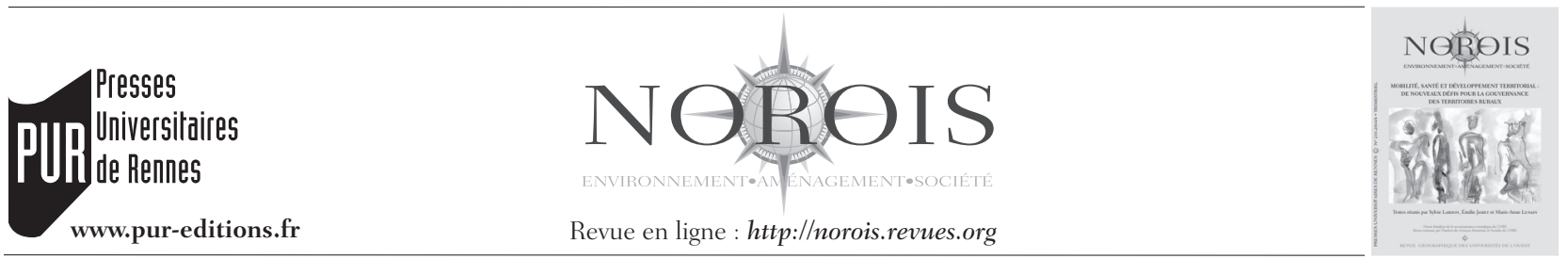

\section{COMPTE RENDU BIBLIOGRAPHiQUe}

\section{Pierrick Graviou, Pierre Jegouzo, Jean Plaine, Max Jonin, 2014, Bretagne, Guide Géologique,} Coédition BRGM-Omniscience, 256 p.

L'ouvrage Bretagne de la série «Guides géologiques » est publié aux éditions Omniscience en collaboration avec BRGM éditions et SGMB, coréalisé par P. Graviou, P. Jégouzo, M. Jonin, J. Plaine et D. Decobecq, en juillet 2014. Ce livre est constitué d'itinéraires de randonnées détaillés d'éléments géologiques, naturels, culturels et patrimoniaux à travers toute la Bretagne. L'ouvrage de 255 pages est divisé en 10 itinéraires : (1) Ploumanac’h, (2) Pleubian, (3) Erquy, (4) Montfort-sur-Meu, (5) Camaret-sur-Mer, (6) Belle-Isle-en-Terre, (7) Le Conquet et Plougonvelin, (8) Pointe du Raz, (9) Île de Groix, (10) Penmarc'h; précédés d'une prestigieuse préface d'Erik Orsenna et d'une brève histoire géologique de la Bretagne. À l'issue de l'ouvrage un glossaire géologique propose les définitions des termes nécessaires à la compréhension des observations géologiques de terrain.

L'histoire géologique de la Bretagne est brièvement retracée en 21 pages clairement illustrées de schémas, de cartes et de photos. Présentés successivement, les roches les plus anciennes de France, les chaînes de montagnes très anciennes érodées par l'érosion au fil des millions d'années, l'ouverture de l'Océan atlantique, le climat tropical précédant les périodes glaciaires nous offrent la Bretagne telle que l'on peut la voir aujourd'hui. Ce chapitre, aussi bien destiné aux connaisseurs qu'aux néophytes, permet d'entrevoir l'histoire évolutive de la Bretagne au travers des forces et contraintes apportées à ses roches. Deux cartes de la Bretagne, l'une géogra-

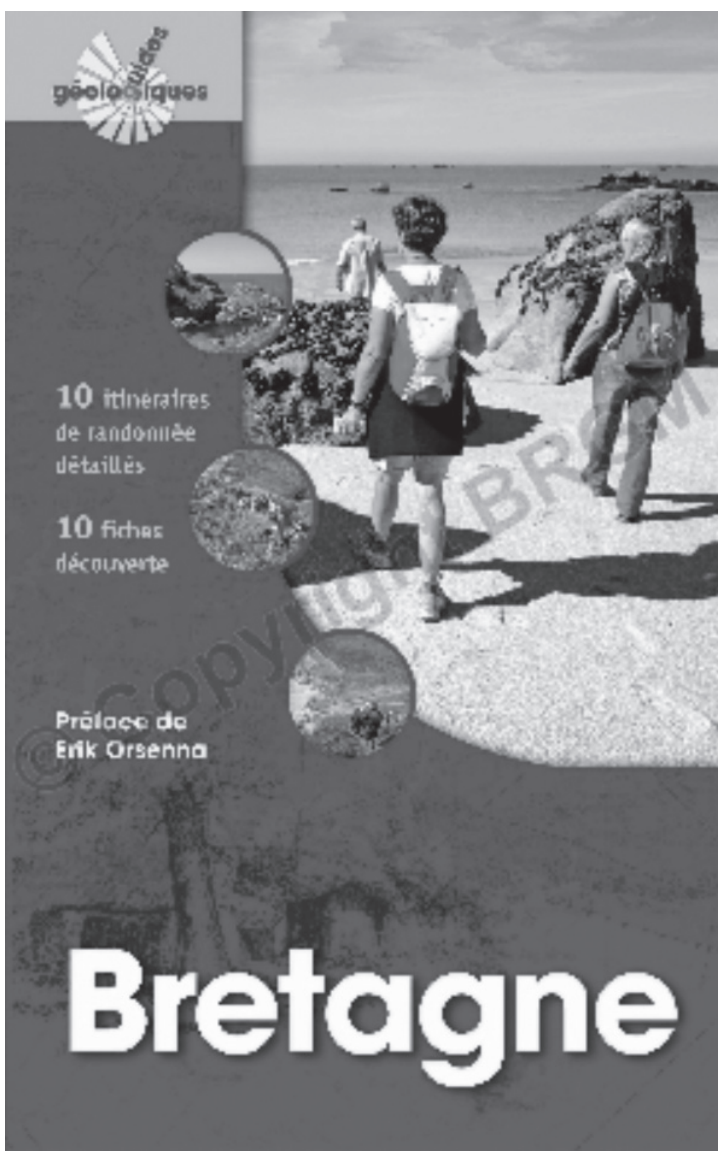

phique sur la couverture, l'autre géologique à la fin du guide, permettent de replacer les itinéraires dans leur contexte orographique régional.

Les itinéraires (1) (2) (3) (5) (7) (8) (9) et (10) proposés dans cet ouvrage jalonnent le littoral bre- 
ton de randonnées face à l'Océan Atlantique ou à la Manche, en proposant des promenades pédestres réalisables en quelques heures, sur une demi-journée. Ces randonnées sont clairement illustrées d'une carte IGN et BRGM, et chaque arrêt proposé au cours des pages de l'itinéraire sont très ponctuellement et clairement annotés sur celle-ci. Ces arrêts proposent d'admirer les roches affleurant les eaux, avec des explications claires et précises sur leur nature, formation, mise en place, et même leur contenu minéralogique voire paléontologique. Compte tenu du caractère " protégé » des sites fossilifères et minéralogiques, des précisions sont apportées aux itinéraires et arrêts pédestres en question. Citons les itinéraires (5) Camaret-sur-Mer avec les structures fossiles remarquables et (9) Ille de Groix avec ses affleurements de grenats, glaucophane, épidote; structures très largement connues et appréciées de nombreux amateurs étrangers.

Les itinéraires (4) et (6) permettent un peu de «magie » dans l'intérieur des terres, avec de magnifiques arrêts dans la forêt de Brocéliande évoquant les légendes associées, ainsi que de remarquables sites témoignant d'une antique anthropisation (mégalithes, églises, maisons anciennes restaurées).

À l'issue de chaque itinéraire, une double page thématique illustre aux randonneurs la vie et les coutumes bretonnes qui font la force culturelle de la Bretagne, à travers les traditions vestimentaires et cultuelles comme les pardons et coiffes, les ressources faunistiques et floristiques (les oiseaux littoraux, le goémon, la pêche à la Saint-Jacques, les calvaires, les légendes), et les produits de la gastronomie locale.

Cet ouvrage a le défaut de ressembler à d'autres livres liés aux littoraux bretons publiés par le BRGM dans la série "Curiosités géologiques ». Ces derniers sont une référence dans les itinéraires publiés à l'intérieur, mais l'ouvrage « Bretagne » ci-présent a le bon sens de reprendre cette présentation en «itinéraires » au travers de la Bretagne, en apportant un nouveau regard sur des sites de grande renommée.

L'ouvrage "Bretagne ", très généreusement illustré de magnifiques photos, de schémas structuraux clairs et colorés donne, à celui qui se le procure, l'envie de partir à la découverte de la région présentée. Les conditions d'affleurements du littoral étant tributaires des marées, il est nécessaire de consulter les horaires des marées avant de commencer la randonnée. L'estran rocheux étant parfois dangereux, malgré le caractère "facile » de certains itinéraires abordables à tout âge, il est nécessaire de posséder l'équipement minimal à toute randonnée (chaussures) et de s'armer de prudence sur les roches.

Maxime HofFMan Université d'Angers 